\title{
La Auto-Eficacia de Profesores en la Composición Escrita
}

\author{
Ellen Lavelle
}

Dpto. de Liderazgo en la Educación, Universidad del Sur de Illinois, Edwardsville

EE.UU.

elavell@siue.edu 


\section{Resumen}

Introducción: Aunque se ha apoyado la "auto-eficacia docente" como constructo importante relacionado con la competencia docente (p.ej. Goddard, Hoy \& Hoy, 2000), se sabe poco sobre cómo los profesores practicantes se ven a sí mismos como escritores, es decir, su autoeficacia en la composición, y en particular la relación de ésta con el rendimiento en la composición. El trabajo actual es un examen preliminar de la relación entre la auto-eficacia del profesor en la composición y su rendimiento en la misma.

Método: Se administró a 64 profesores la Low Self-Efficacy Scale [Escala de Baja Autoeficacia] (Lavelle y Guarino, 2003), la cual mide creencias de los adultos sobre su competencia en la composición. Todos los profesores están matriculados actualmente en un curso de post-graduado, donde un trabajo de investigación académica forma parte de los requisitos normales del curso, así que sirvieron como variables de nuestra investigación tanto las puntuaciones de la escala como los resultados de su trabajo escrito. Se prepararon a dos calificadores para que evaluasen la muestra de composición según dos medidas: una rúbrica holística diseñada para reflejar la competencia general en la composición, y una rúbrica profunda y superficial que mide la estructura de la composición, la audiencia y la implicación personal.

Resultados: El análisis de datos se trataba de examinar la correlación entre la calidad de la composición, medida por la rúbrica holística, y las puntuaciones de la escala de baja autoeficacia, y una consideración de las diferencias entre los resultados profundos y superficiales de la composición, tomando como variable dependiente las puntuaciones de la escala. Los resultados apoyan la relación entre la auto-eficacia en la composición, y el rendimiento en la misma, según las medidas de las dos rúbricas.

Discusión y Conclusión: Las conclusiones apoyan el hipótesis con respecto a la relación de la capacidad compositora y la auto-eficacia, vinculadas a cada una de las dos rúbricas. Se comentan implicaciones, para futuras investigaciones.

Palabras clave: auto-eficacia, creencias docentes, habilidades de composición, educación pos-graduada 